\title{
Necessidade de irrigação para o feijoeiro na região central do Rio Grande do Sul ${ }^{1}$
}

\author{
Joel C. da Silva ${ }^{2}$, Arno B. Heldwein ${ }^{3}$, Sidinei Z. Radons ${ }^{4}$, Ivan C. Maldaner ${ }^{3}$, \\ Gustavo Trentin ${ }^{5}$ \& Edenir L. Grimm ${ }^{6}$
}

\begin{abstract}
RESUMO
A falta de conhecimento da probabilidade de ocorrência de adversidades climáticas representa um problema para o planejamento da produção do feijoeiro. Este estudo objetivou determinar os valores de lâmina de irrigação e do número de irrigações necessários para o feijão semeado em diferentes épocas, considerandose a capacidade de armazenamento de água disponível (CAD) dos principais solos da região Central do Rio Grande do Sul. A simulação do ciclo foi realizada utilizando-se a soma térmica, em dez épocas de semeadura (ES) e em cada ano da série histórica de dados meteorológicos, para o período entre 1968 e 2006. A irrigação foi simulada para 13 solos da região de abrangência da estação meteorológica de Santa Maria, que foram reunidos em seis grupos. Para simular a irrigação utilizaram-se quatro manejos: 0,$8 ; 0,7$; 0,6 e 0,5 os quais correspondem ao esgotamento máximo de $20,30,40$ e $50 \%$ da CAD, respectivamente. A variação do conteúdo de água no solo foi determinada pelo balanço hídrico diário do solo, considerandose a irrigação. A maior exigência de irrigação ocorreu nas últimas ES do período da safra e a menor no início da safra e na safrinha. Para a probabilidade de $90 \%$ de ocorrência a lâmina de irrigação variou entre 32 e $143 \mathrm{~mm}$ e o número de irrigações entre 3 e 20, durante o ciclo de cultivo.
\end{abstract}

Palavras-chave: Phaseolus vulgaris L., estresse hídrico, capacidade de armazenamento de água disponível (CAD)

\section{Irrigation necessity for common bean in central region of Rio Grande do Sul}

\begin{abstract}
The lack of knowledge about the likelihood of occurence of bad weather is a problem for production planning of the bean. This study aimed to determine the values of water depth and number of irrigations required for common bean at different sowing times, considering the storage capacity of available water (CAD) of the main soils of central region of Rio Grande do Sul. The cycle simulation was performed using the thermal time in ten sowing times (ES) and in each year of the historical series of meteorological data for the period between 1968 and 2006. Irrigation was simulated for 13 soils of the region covered by meteorological station of Santa Maria, which were grouped in six groups. To simulate the irrigation, four handlings were used: 0.8 , $0.7,0.6$ and 0.5 corresponding to the maximum depletion of $20,30,40$ and $50 \%$ of CAD, respectively. The variation of soil water content was determined by soil water balance, considering the irrigation. The greater demand for irrigation occurred in last sowing times of the main crop season and lowest at the begining of the main and second crop season. For the $90 \%$ probability of occurrence of the water depth ranged between 32 and $143 \mathrm{~mm}$ and the number of irrigations between 3 and 20 during cycle.
\end{abstract}

Key words: Phaseolus vulgaris L., water stress, available water storage capacity (AWSC)

Parte da Tese de Doutorado em Engenharia Agrícola, do primeiro autor

2 Instituto Federal Farroupilha, Campus de São Vicente do Sul. Rua 20 de Setembro, CEP 97420-000, São Vicente do Sul, RS. Fone: (55) $3257-1114$. E-mail: jcsilva@svs.iffarroupilha.edu.br

Departamento de Fitotecnia/UFSM. Avenida Roraima n 1000, Prédio 77, Cidade Universitária, Bairro Camobi, Santa Maria, RS, CEP $97105-900$. Fone: (55) 3220-8179. E-mail: heldweinab@smail.ufsm.br, ivan_maldaner@yahoo.com.br

Universidade Federal da Fronteira Sul, Campus Cerro Largo. Rua Major Antônio Cardoso, 570, CEP 97900-000, Cerro Largo, RS. Fone: (55) $3359-3978$. E-mail: radons@uffs.edu.br

Embrapa Pecuária Sul. BR 153, Km 603, C.P. 242, Vila Industrial, CEP 96401-970, Bagé, RS. Fone/Fax: (53) 3240-4650. E-mail: gustavo.trentin@cppsul.embrapa.br

${ }^{6}$ Instituto Federal Farroupilha, Campus de Alegrete. RS 377, Km 27, Passo Novo, CEP 97555-000, Alegrete, RS. Fone: (55) 3421-9600. Email: edenirgrimm@al.iffarroupilha.edu.br 


\section{INTRODUÇÃO}

O feijoeiro é cultivado em todas as partes do território brasileiro. Os grãos produzidos são muito consumidos no País, geralmente em combinação com o arroz, fonte de amido o que constitui um equilíbrio na dieta, pois o feijão é uma fonte acessível de proteína. O cultivo dessa leguminosa ocorre, na maioria das regiões, em pequenas propriedades, com áreas entre 1 a 50 hectares, porém há um crescente interesse para a produção em áreas irrigadas e de maior extensão (EMBRAPA, 2003).

Apesar de sua grande importância para a maioria da população brasileira, a produção de feijão é variável entre os anos e comumente se observam perturbações e inconstância no seu cenário comercial. A variação anual da produção pode ser devida ao desconhecimento em relação às condições meteorológicas ao longo do período produtivo e nos locais de produção (EMBRAPA, 2003).

A incerteza ou o desconhecimento das condições meteorológicas e da probabilidade de ocorrência de adversidades climáticas tem sido tema constante de preocupação no setor primário para que as principais decisões técnicas, econômicas, administrativas e políticas possam ser tomadas de forma adequada e em tempo hábil o que em muitos casos pode levar meses ou anos para que a atividade seja efetuada.

O rendimento médio do feijoeiro no Brasil, em particular no Rio Grande do Sul, é considerado baixo e seguramente pode ser aumentado com o entendimento das variáveis de ambiente que limitam o potencial de rendimento, o zoneamento de riscos climáticos e a adoção de práticas culturais que possibilitem melhor aproveitamento das condições disponíveis (Maluf et al., 2001).

O estresse hídrico é a principal causa do baixo rendimento do feijoeiro. Essa leguminosa consome aproximadamente 300 mm de água durante o ciclo (Matzenauer et al., 1999) e é uma espécie muito sensível a ambientais extremos, sobretudo durante o florescimento em relação à temperatura (Silva et al., 2007) e deficiência hídrica (Bergamaschi et al.,1988; EMBRAPA, 2003). Isto ocorre devido às suas limitações anatômicas e fisiológicas, ou seja, pela baixa capacidade de recuperação após a deficiência hídrica e também pelo sistema radicular pouco desenvolvido. A ocorrência de deficiência hídrica no RS para o feijoeiro é frequente, podendo se esperar redução no rendimento de grãos desta cultura, em duas a cada dez safras (Matzenauer et al., 2004).

Com a aplicação da técnica da modelagem de desenvolvimento e crescimento das culturas em diferentes condições meteorológicas locais e para os solos da região, é possível estimar a provável lâmina de água e o provável número de irrigações para qualquer época de semeadura.

O objetivo foi determinar os prováveis valores de lâmina de irrigação e do número de irrigações necessários para o feijoeiro semeado em diferentes épocas, considerando-se a capacidade de armazenamento de água disponível (CAD) dos principais solos da região central do RS.

\section{MATERIAL E MÉTODOS}

A região de estudo é a área de abrangência da Estação Meteorológica Principal de Santa Maria (EMPSM), definida em Cardoso (2005), entre as coordenadas de $29^{\circ} 23^{\prime} 15^{\prime \prime} \mathrm{S}$ e $30^{\circ} 22^{\prime} 17^{\prime}$ ' S, $54^{\circ} 32^{\prime} 07^{\prime \prime}$ W e $53^{\circ} 05^{\prime} 20^{\prime \prime} \mathrm{W}$, totalizando aproximadamente $8000 \mathrm{~km}^{2}$. Nesta área estão compreendidos integralmente os municípios de Santa Maria, São Pedro do Sul, Dilermando de Aguiar, São Martinho da Serra, Itaara, Silveira Martins, São João do Polêsine, Restinga Seca e Formigueiro. Também são abrangidos, em parte, os municípios de São Sepé, Santa Margarida do Sul, São Gabriel, Cacequi, Júlio de Castilhos, Ivorá e Faxinal do Soturno.

A maior parte da superfície desta região é ocupada por Argissolos, unidades de mapeamento Alto das Canas, Júlio de Castilhos, Oásis, Santa Maria e São Pedro, seguidos dos Planossolos (Vacacaí e São Gabriel) e demais solos (Neosolo, Chernossolo, Luvissolo e Latossolo), ocupando aproximadamente 51, 34 e 15\% da área, respectivamente.

Os cálculos foram realizados de forma seriada utilizando-se dados diários de evapotranspiração calculada pelo método de Penman, precipitação pluviométrica diária e a capacidade de armazenamento de água disponível do solo (CAD), considerando-se sua variação em função do tipo de solo e do desenvolvimento das plantas do feijoeiro simulado para as diferentes épocas de semeadura.

Para o cálculo do balanço hídrico $(\mathrm{BH})$, a metodologia empregada e o roteiro de cálculo foram similares aos utilizados por Nied et al. (2005) e Silva et al. (2006), com a diferença de que o cálculo foi realizado iterativamente para obtenção da lâmina de irrigação necessária no dia "n", baseado no conteúdo de água armazenado no solo no dia "n-1". A lâmina de irrigação, quando existente, foi adicionada à precipitação, sendo ambas consideradas entradas de água no cálculo do $\mathrm{BH}$.

A quantidade de água que realmente contribui para o armazenamento da água no solo, é a que infiltra depois de uma precipitação. A consideração de todas as combinações de situações práticas possíveis de acontecer em relação à infiltração de água no solo, é uma situação de difícil contorno pois este parâmetro do solo tem uma variação espacial muito grande, mesmo em áreas homogêneas, quanto ao tipo de solo, manejo e relevo. Além disso, a consideração de todas as situações possíveis para vários tipos de solo e diferentes manejos de irrigação, geraria um número muito grande (infinito) de combinações. Porém, uma maneira de se considerar pelo menos em parte esta variação, foi determinar a precipitação efetiva (Frizzone et al., 2005).

O cálculo da necessidade de irrigação foi realizado pelo quociente entre o conteúdo atual de água no solo e a CAD. Assim, a determinação do momento de irrigar foi realizada de acordo com a umidade existente no solo, ou seja, conforme a relação dada pelo quociente entre a umidade atual e a CAD calculada para o dia n e de acordo com o nível de depleção de água previamente estabelecido para o manejo de irrigação. Exemplificando: quando o quociente descresceu e atigiu o valor de 0,6 foi simulada uma irrigação para o manejo de irrigação " 0,6 ". 
Os diferentes manejos de irrigação (i) foram: 0,5; 0,6;0,7 e $0,8 \mathrm{~mm} \mathrm{~mm}^{-1}$, os quais correspondem à retirada de água disponível armazenda no solo de no máximo 50, 40, 30 e 20\% da CAD, respectivamente. Desta forma, a água prontamente disponível às plantas $(\mathrm{AD})$, para o processo de evapotranspiração, foi estabelecida pelo manejo de irrigação:

$$
\mathrm{AD}=(1-\mathrm{i}) \mathrm{CAD}
$$

em que: $(1-i)=p$ - fração de esgotamento de água no solo para os níveis de irrigação (i). Os valores de p foram definidos dentro da faixa para a cultura do feijão (Doorembos \& Kassam, 1994): $\mathrm{p}=0,5 ; \mathrm{p}=0,4 ; \mathrm{p}=0,3$ e $\mathrm{p}=0,2$ para os níveis de irrigação: $\mathrm{i}=0,5 ; \mathrm{i}=0,6 ; \mathrm{i}=0,7 \mathrm{e} \mathrm{i}=0,8$, respectivamente.

A simulação do desenvolvimento da cultura foi realizada para cada solo utilizando-se diferentes manejos de irrigação e diferentes épocas de semeadura, sempre no $1^{\circ}$ e $15^{\circ}$ dia do mês, durante o período de semeadura recomendado pela pesquisa para cada época de cultivo, safra ou safrinha.

Os períodos de semeadura utilizados foram semelhantes aos indicados como períodos favoráveis de semeadura para o feijão, por Maluf et al. (2001), entre 11 de agosto até 10 de novembro para a safra e entre 11 de janeiro e 28 de fevereiro para a safrinha.

Para o cálculo da evapotranspiração máxima da cultura utilizaram-se a evapotranspiração de referência calculada e os coeficientes de cultura para o feijoeiro determinados por Matzenauer et al. (1999). Os coeficientes de cultura (Kc) foram calculados por equações lineares considerando-se o intervalo entre os subperíodos: Semeadura - Primeira Folha Trifoliada; Primeira Folha Trifoliada - Início da Floração; Início da Floração - Início do enchimento de grãos; Início do enchimento de grãos - Maturação Fisiológica (Tabela 1), as equações lineares foram estimadas a partir dos valores determinados por Matzenauer et al. (1999) para os subperíodos, de forma que houvesse uma transição gradual dos valores de $\mathrm{Kc}$, durante o ciclo.

Determinou-se a duração dos subperíodos pelo cálculo da soma térmica acumulada, o qual foi realizado pelo somatório das unidades térmicas diárias, quantificadas pela diferença entre a média das temperaturas extremas do ar (máxima e mínima) e a temperatura base, assumida como igual a $10^{\circ} \mathrm{C}$ (Medeiros et al., 2000). A partir do cálculo da soma térmica definiram-se os subperíodos e os valores de Kc (Tabela 1).

Para o cálculo da água disponível no solo visando à cultura do feijoeiro, os valores diários da capacidade de armazenamento de água disponível do solo (CAD) foram variáveis, conforme o aprofundamento radicular.
Durante o subperíodo semeadura-emergência considerouse a CAD até a profundidade de $0,10 \mathrm{~m}$; durante o subperíodo início da floração-maturação fisiológica, foi considerada a CAD até a máxima profundidade radicular (CADf) e durante o subperíodo emergência-início da floração, a CAD foi calculada para cada dia (CADn), simulando-se o aprofundamento radicular progressivo, pela equação proposta por Oliveira \& Villa Nova (1996).

Os valores de CAD inicial e final foram calculados para os distintos solos, utilizando-se os valores de capacidade de campo e o ponto de murcha permanente descritos para os diferentes horizontes e solos, com base nas informações encontradas em Streck et al. (2008) e Cardoso (2005). A CAD foi determinada para a profundidade de $0,10 \mathrm{~m}$ enquanto a $\mathrm{CAD}_{\mathrm{f}}$ foi determinada até a profundidade de $0,50 \mathrm{~m}$ quando a presença natural de raízes era abundante ou não havia nenhum impedimento químico ou físico para as raízes atingirem a camada até $0,50 \mathrm{~m}$ ou, em caso contrário, até $0,40 \mathrm{~m}$ (Oliveira \& Villa Nova, 1996). A partir do cálculo das $\mathrm{CAD}(\mathrm{s})$, os solos da região foram agrupados em classes, conforme o valor da $\mathrm{CAD}_{\mathrm{in}}$ e $\mathrm{CAD}_{\mathrm{f}}$ (Tabela 2).

Tabela 2. Capacidade de armazenamento de água disponível no solo, inicial $\left(\mathrm{CAD}_{\mathrm{in}}\right)$ e final (CADf), valor da curva $(\mathrm{CN})$, unidades de mapeamento e classificação dos solos (Streck et al., 2008) da área de abrangência da estação climatológica principal de Santa Maria, RS, utilizados no estudo simulado para os anos de 1968 a 2006

\begin{tabular}{|c|c|c|c|c|}
\hline \multicolumn{2}{|c|}{$\begin{array}{c}\mathrm{CAD}_{\text {in }} \text { CAD }_{\mathrm{f}} \\
(\mathrm{mm})\end{array}$} & \multicolumn{2}{|r|}{$\mathrm{N} \begin{array}{c}\text { Unidades de } \\
\text { mapeamento }\end{array}$} & Classificação dos solos \\
\hline 15 & 60 & 72 & São Pedro & Argissolo Vermelho Distrófico arênico \\
\hline 15 & 60 & 72 & Venda Grande & Chernossolo Argilúvico Órtico saprolítico \\
\hline 15 & 60 & 72 & Cerrito & Latossolo Vermelho Distrófico típico \\
\hline 15 & 100 & 72 & Vacacaí & Planossolo Háplico Eutrófico arênico \\
\hline 22 & 80 & 72 & Santa Maria & Argissolo Amarelo Alítico típico \\
\hline 15 & 45 & 91 & Charrua & Neossolo Litólico Eutrófico típico \\
\hline 15 & 45 & 91 & Ciríaco & Chernossolo Argilúvico Férrico típico \\
\hline 15 & 45 & 91 & Guassupi & Neossolo Litólico Distró-úmbrico típico \\
\hline 15 & 45 & 91 & Júlio de Cast & Argissolo Vermelho-amarelo Alumínico úmbrico \\
\hline 15 & 70 & 91 & Alto das Canas & Argissolo Vermelho-amarelo Distrófico úmbrico \\
\hline 15 & 70 & 91 & Cambai & Luvissolo Crômico Pálico saprolítico \\
\hline 22 & 80 & 91 & Oásis & Argissolo Bruno-acinzentado Alumínico típico \\
\hline 22 & 80 & 91 & São Gabriel & Planossolo Háplico Eutrófico vertissólico \\
\hline
\end{tabular}

Utilizando as simulações de desenvolvimento da cultura $(\mathrm{Kc})$, para o cálculo da variação do Kc e variação do CAD e considerando o aprofundamento radicular, obtiveram-se os valores de irrigação simulada pelo cálculo iterativo do balanço hídrico diário, conforme metodologia anteriormente descrita,

Tabela 1. Soma térmica acumulada (ST), subperíodos de desenvolvimento e modelo de cálculo dos coeficientes de cultura utilizados para determinar a evapotranspiração máxima do feijoeiro, conforme Matzenauer et al. (1999) e Medeiros et al. (2000)

\begin{tabular}{clc}
\hline Soma térmica ( ${ }^{\circ} \mathbf{C}$ dia) & \multicolumn{1}{c}{ Subperíodos } & Coeficiente de cultura \\
$0-94$ & Semeadura - Primeira folha trifoliada & $0,40+2,447\left(10^{-3}\right)$ ST \\
$94-246$ & Primeira folha trifoliada - terceira folha trifoliada & $0,57+5,936\left(10^{-4}\right)$ ST \\
$246-532$ & Terceira folha trifoliada - Início da floração & $0,57+5,936\left(10^{-4}\right)$ ST \\
$532-653$ & Início da floração - Início formação vagens & 0,89 \\
$653-812$ & Início formação vagens - Início enchimento de grãos & 0,89 \\
$812-1155$ & Início de enchimento Grãos - Maturação fisiológica & $1,01-1,458\left(10^{-4}\right)$ ST \\
\hline
\end{tabular}


para os diferentes solos, manejos de irrigação (i) e épocas de semeadura (ES) e em cada ano. Esses valores foram somados para todos os anos agrícolas, obtendo-se a lâmina de irrigação requerida para o feijoeiro e se contabilizaram o número de irrigações por período de cultivo e a relação entre o número de anos em que foi necessário irrigar e o total de anos da simulação, para cada solo, manejo de irrigação e ES.

As lâminas de irrigação e o número de irrigações foram submetidos à análise de variância, adotando-se o delineamento inteiramente casualizado e se considerando cada ano do banco de dados como uma repetição e teste de Tukey, a nível de 5\% de significância. Para a lâmina de irrigação e o número de irrigações, as fontes de variação foram os tipos de solo, épocas de semeadura, níveis de manejo de irrigação e respectivas interações.

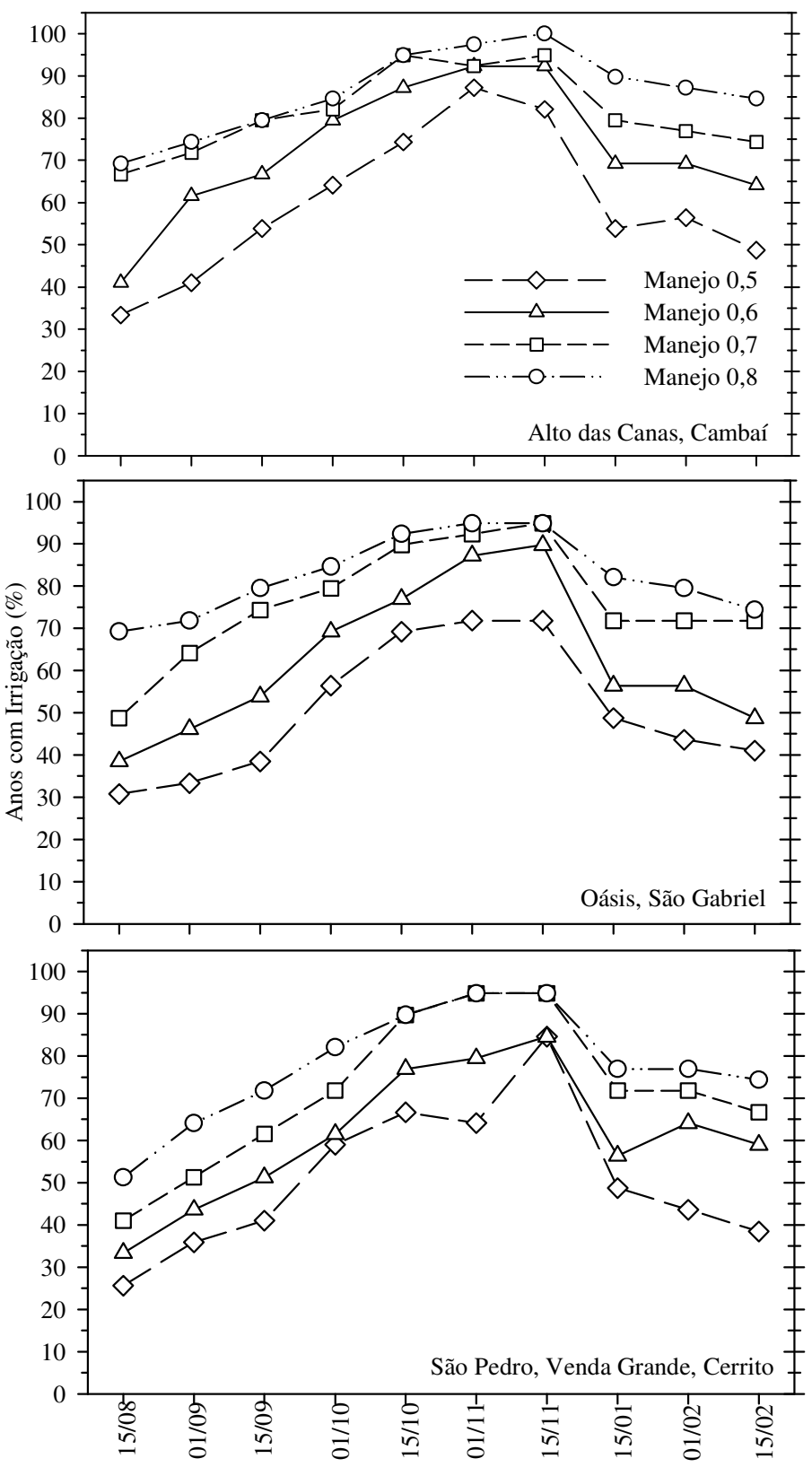

\section{RESULTADOS E DISCUSSÃO}

Constatou-se diferença significativa entre: solos, manejos de irrigação, épocas de semeadura e interação entre solos e manejo de irrigação e entre solos e épocas de semeadura.

Na Figura 1 se encontram os percentuais de anos agrícolas (PA) em que foi necessário irrigar, para os diferentes solos e manejos de irrigação, em função das ES. Para todos os solos houve aumento de PA ao longo da safra (de 15/08 a 15/11) e leve diminuição ao longo da safrinha.

A irrigação foi mais frequente para os solos Charrua, Ciríaco, Guassupi e Júlio de Castilhos, com valores maiores que 60\% dos anos para a maioria das ES, e menos frequente para o solo Vacacaí. Os primeiros solos citados são solos com baixa CAD,
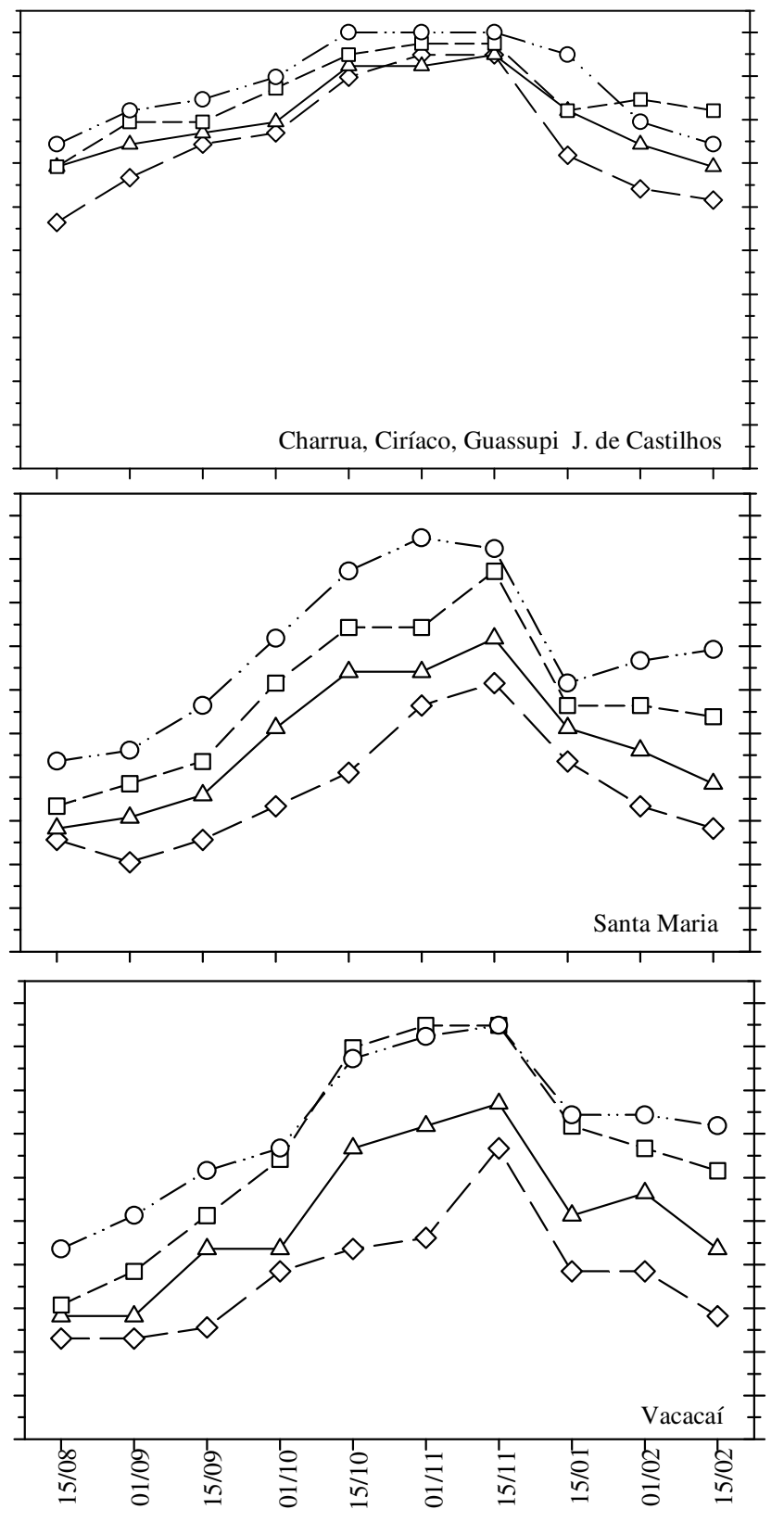

Semeadura

Figura 1. Percentual de anos agrícolas em que foi necessária pelo menos uma irrigação, para os diferentes solos, manejos de irrigação e épocas de semeadura, simuladas em cada ano do período entre 1968 e 2006 
com impedimentos ao aprofundamento radicular e baixa taxa de infiltração de água no solo, enquanto o solo Vacacaí é um solo profundo e com CAD alta (Cardoso, 2005).

Considerando o manejo de irrigação " 0,6 " o percentual aproximado de anos com irrigação variou entre 40 e $90 \%$ para os solos, Alto das Canas e Cambaí; entre 70 e $95 \%$ para os solos, Charrua, Ciríaco, Guassupi e Júlio de Castilhos, entre 40 e 90\%, para os solos Oásis e São Gabriel, entre 25 e 70\%, para o solo Santa Maria, entre 35 e $85 \%$ dos anos para os solos São Pedro, Venda Grande e Cerrito e entre 28 e $77 \%$ para o solo Vacacaí (Figura 1).

A comparação entre solos para as médias de irrigação e número de irrigações, é apresentada na Tabela 3. Não houve diferença estatisticamente significativa para os valores de lâmina de irrigação, entre os solos Alto das Canas, Cambaí, Charrua, Ciríaco, Guassupi, Júlio de Castilhos, Oásis e São Gabriel, com aproximadamente $53 \mathrm{~mm}$ de necessidade de irrigação por cultivo, nem entre os solos Santa Maria, São Pedro, Venda Grande, Cerrito e Vacacaí, com aproximadamente $45 \mathrm{~mm}$ de necessidade de irrigação. Esta separação em dois agrupamentos se deve, provavelmente, à semelhança de textura entre os solos dos dois grupos, a qual resultou, possivelmente, da consideração de diferentes infiltrações de água no solo, para cada grupo, diferença considerada no cálculo da precipitação efetiva, modelada a partir dos valores de CN (Tabela 3).

Tabela 3. Valores médios de lâmina de irrigação ( $\mathrm{mm})$ e do número de irrigações, totalizados em cada período de cultivo e solos estudados na simulação do ciclo do feijoeiro, durante o período de 1968 a 2006

\begin{tabular}{lll}
\hline \multicolumn{1}{c}{ Solo } & $\begin{array}{c}\text { Irrigação } \\
(\mathbf{m m})\end{array}$ & $\begin{array}{c}\text { Num. } \\
\text { Irrig. }\end{array}$ \\
Alto das Canas, Cambaí & $53,7 \mathrm{~A}$ * & $3,8 \mathrm{~B}$ \\
Charrua, Ciríaco, Guassupi, Júlio de Castilhos & $53,7 \mathrm{~A}$ & $4,6 \mathrm{~A}$ \\
Oásis, São Gabriel & $52,5 \mathrm{~A}$ & $2,9 \mathrm{C} \mathrm{D}$ \\
Santa Maria & $44,5 \mathrm{~B}$ & $2,6 \mathrm{D}$ \\
São Pedro, Venda Grande, Cerrito & $45,3 \mathrm{~B}$ & $3,6 \mathrm{~B}$ \\
Vacacaí & $45,5 \mathrm{~B}$ & $3,1 \mathrm{C}$ \\
\hline
\end{tabular}

* Médias não seguidas de mesma letra na vertical, diferem pelo teste de Tukey em nível de $5 \%$ de probabilidade de erro

Quanto ao número de irrigações, observou-se um número maior para os solos Charrua, Ciríaco, Guassupi e Júlio de Castilhos com aproximadamente cinco irrigações, seguidos dos solos Alto das Canas, Cambaí, São Pedro, Venda Grande e Cerrito, com aproximadamente quatro irrigações e os demais com uma média aproximada de três irrigações por cultivo (Tabela 3).

A diferença entre o número de irrigações para cada grupo de solos mostra que, mesmo havendo semelhança entre as médias dos totais de irrigação, poderá ocorrer diferenças entre os solos para a lâmina de irrigação requerida em cada aplicação. Nos solos com menor CAD a irrigação é mais frequente, porém a quantidade de água necessária para completar a CAD é menor, pois o conteúdo de água armazenado na saturação é menor nesses casos. Nos solos com maior CAD a irrigação é menos frequente, mas o volume de água necessário para repor o conteúdo de água até completar a $\mathrm{CAD}$, é maior, razão por que a lâmina total de água foi semelhante nos dois casos, embora o número de aplicações seja diferente.
Na comparação dos valores de irrigação e número de irrigações entre ES (Tabela 4), o comportamento foi semelhante para as duas variáveis. A lâmina de irrigação e o número de aplicações foram maiores nas ES de 01/11 e 15/11, aproximadamente $60 \mathrm{~mm}$ e cinco aplicações, embora nessas épocas o ciclo seja mais curto.

Tabela 4. Valores médios de lâmina de irrigação ( $\mathrm{mm})$ e do número de irrigações, totalizados em cada período de cultivo e épocas de semeadura estudadas na simulação do ciclo do feijoeiro, durante o período de 1968 a 2006

\begin{tabular}{lcc}
\hline Época de semeadura & Irrigação (mm) & Num. Irrig. \\
15 de agosto & $46,9 \mathrm{E}^{\star}$ & $2,6 \mathrm{~F}$ \\
01 de setembro & $50,8 \mathrm{D} \mathrm{E}$ & $2,9 \mathrm{E} \mathrm{F}$ \\
15 de setembro & $53,2 \mathrm{C} \mathrm{D}$ & $3,2 \mathrm{D} \mathrm{E}$ \\
01 de outubro & $55,0 \mathrm{~B} \mathrm{C} \mathrm{D}$ & $3,5 \mathrm{C} \mathrm{D}$ \\
15 de outubro & $56,1 \mathrm{~B} \mathrm{C}$ & $3,8 \mathrm{C}$ \\
01 de novembro & $60,5 \mathrm{~A}$ & $4,2 \mathrm{~B}$ \\
15 de novembro & $59,1 \mathrm{~A} \mathrm{~B}$ & $4,8 \mathrm{~A}$ \\
15 de janeiro & $39,6 \mathrm{~F}$ & $3,6 \mathrm{C}$ \\
01 de fevereiro & $32,6 \mathrm{G}$ & $2,8 \mathrm{E} \mathrm{F}$ \\
15 de fevereiro & $26,8 \mathrm{H}$ & $2,5 \mathrm{~F}$ \\
\hline
\end{tabular}

* Médias não seguidas de mesma letra na vertical, diferem pelo teste de Tukey em nível de 5\% de probabilidade de erro

A maior necessidade de suplementação hídrica para as ES de 01/11 e 15/11se deve, provavelmente, à maior disponibilidade de energia solar e ao maior aquecimento do ar, em virtude da aproximação do verão, e a coincidência do período de maior exigência de água pela planta, próximo à floração (Matzenauer et al., 1999) com a época do ano em que a demanda evaporativa da atmosfera é mais elevada (Heldwein et al., 2009).

Situação contrária ocorreu para as ES da safrinha (15/01, 01/ 02 e 15/02), épocas em que se obtiveram os menores valores de irrigação e número de irrigações, aproximadamente 40, 33 e 27 $\mathrm{mm}$, aplicados em quatro, três e três vezes, para as ES de 15/01, 01/02 e 15/02, respectivamente, embora o ciclo seja mais longo nessas ES.

Este comportamento foi observado em virtude do ciclo das plantas cultivadas na safrinha ocorrer no final do verão e outono, enquanto a necessidade de água das plantas aumenta, a demanda evaporativa da atmosfera diminui, não ocorrendo coincidência entre os períodos; as demais ES tiveram valores intermediários entre os extremos, para as variáveis analisadas.

Na comparação entre os manejos de irrigação para a lâmina e número de irrigações, verificou-se diferença estatisticamente significativa entre todos os manejos, situação esta prevista, pois os manejos de irrigação diferenciados pressupõem aplicação de diferentes lâminas de irrigação, enquanto no manejo 0,5 a irrigação é realizada somente quando o conteúdo de água no solo atinge $50 \%$ da CAD, no manejo 0,8 a irrigação é prevista para quando forem consumidos $20 \%$ da CAD ou o conteúdo atual de água no solo esteja a $80 \%$ da CAD, calculada para aquele dia.

Houve efeito da interação entre os solos e o manejo de irrigação. Assim, realizou-se a comparação das médias de lâmina de irrigação e de número de irrigações entre manejos de irrigação, para cada solo (Tabela 5). Para os solos Alto das Canas e Cambaí, a lâmina de irrigação determinada foi maior para o 
manejo 0,8 (63,1 mm), não havendo diferença estatisticamente significativa entre os manejos 0,7 e 0,6 e nem entre os manejos 0,6 e 0,5 . O menor valor de lâmina de irrigação foi para o manejo 0,5 (43,5 mm), comportamento idêntico ao observado para os solos Oásis e São Gabriel (Tabela 5).

Tabela 5. Valores médios de lâmina de irrigação $(\mathrm{mm})$ e do número de irrigações, totalizados em cada período de cultivo para cada manejo de irrigação e solo, estudados na simulação do ciclo do feijoeiro, durante o período de 1968 a 2006

\begin{tabular}{lccc}
\hline \multicolumn{1}{c}{ Solo } & Manejo $^{1}$ & Irrigação (mm) & Num. Irrig. \\
Alto das Canas, & 0,5 & $43,5 \mathrm{C}$ & $1,9 \mathrm{D}$ \\
Cambai & 0,6 & $49,6 \mathrm{~B} \mathrm{C}$ & $2,5 \mathrm{C}$ \\
& 0,7 & $55,1 \mathrm{~B}$ & $3,7 \mathrm{~B}$ \\
& 0,8 & $63,1 \mathrm{~A}$ & $6,1 \mathrm{~A}$ \\
\hline Charrua, Ciríaco, & 0,5 & $43,6 \mathrm{C}$ & $2,4 \mathrm{D}$ \\
Guassupi, Júlio de & 0,6 & $49,8 \mathrm{C}$ & $3,3 \mathrm{C}$ \\
Castilhos & 0,7 & $56,4 \mathrm{~B}$ & $4,9 \mathrm{~B}$ \\
& 0,8 & $63,2 \mathrm{~A}$ & $7,4 \mathrm{~A}$ \\
\hline Oásis, São Gabriel & 0,5 & $44,7 \mathrm{C}$ & $1,5 \mathrm{C}$ \\
& 0,6 & $48,8 \mathrm{~B} \mathrm{C}$ & $2,0 \mathrm{C}$ \\
& 0,7 & $53,2 \mathrm{~B}$ & $2,8 \mathrm{~B}$ \\
& 0,8 & $59,4 \mathrm{~A}$ & $4,6 \mathrm{~A}$ \\
\hline Santa Maria & 0,5 & $39,2 \mathrm{~B}$ & $1,4 \mathrm{C}$ \\
& 0,6 & $42,6 \mathrm{~A}$ & $1,8 \mathrm{C}$ \\
& 0,7 & $44,9 \mathrm{~A}$ & $2,5 \mathrm{~B}$ \\
& 0,8 & $48,4 \mathrm{~A}$ & $3,9 \mathrm{~A}$ \\
\hline São Pedro, Venda & 0,5 & $39,8 \mathrm{C}$ & $1,9 \mathrm{C}$ \\
Grande e Cerrito & 0,6 & $42,0 \mathrm{C}$ & $2,5 \mathrm{C}$ \\
& 0,7 & $46,0 \mathrm{~B}$ & $3,5 \mathrm{~B}$ \\
& 0,8 & $51,1 \mathrm{~A}$ & $5,6 \mathrm{~A}$ \\
\hline Vacacaí & 0,5 & $38,7 \mathrm{~B}$ & $1,6 \mathrm{C}$ \\
& 0,6 & $40,5 \mathrm{~B}$ & $1,9 \mathrm{C}$ \\
& 0,7 & $45,8 \mathrm{~B}$ & $3,2 \mathrm{~B}$ \\
& 0,8 & $52,4 \mathrm{~A}$ & $4,5 \mathrm{~A}$ \\
\hline
\end{tabular}

${ }^{1}$ Fração da CAD que foi mantida no solo, com a simulação de irrigação

* Médias não seguidas de mesma letra na vertical, diferem pelo teste de Tukey em nível de $5 \%$ de probabilidade de erro

Constatou-se semelhança na comparação entre as médias de lâmina de irrigação para os solos Charrua, Guassupi, Ciríaco, Guassupi, Júlio de Castilhos e São Pedro, Venda Grande e Cerrito. A maior média foi para o manejo 0,8 , seguido do manejo 0,7 e dos manejos 0,6 e 0,5 . Os dois últimos não apresentaram diferença estatística significativa entre si (Tabela 5).

Ao comparar as médias de lâmina de irrigação entre os manejos para o solo Santa Maria, observou-se que não houve diferença significativa entre os manejos $0,6,0,7$ e 0,8 e que esses manejos diferem estatisticamente do manejo 0,5 , com menor lâmina de irrigação requerida (Tabela 5).

Para o solo Vacacaí, os manejos 0,5, 0,6 e 0,7 não diferiram entre si quanto à lâmina de irrigação e o manejo 0,8 possui o maior valor da variável (Tabela 5).

De maneira geral, para a maioria dos solos a lâmina de irrigação foi maior para o manejo 0,8, o qual, com exceção para o solo Santa Maria, diferiu estatisticamente dos demais que, geralmente, apresentaram valores semelhantes quando comparados entre si. Para o solo Santa Maria o único valor que diferiu dos demais foi a lâmina de irrigação média determinada para o manejo 0,5 (Tabela 5).
Na comparação das médias do número de irrigações entre os manejos de irrigação, para cada solo, nota-se que existem dois grandes grupos de solos, cada um com comportamento idêntico. Para os solos Alto das Canas, Cambaí, Charrua, Ciríaco, Guassupi e Júlio de Castilhos, os manejos foram todos diferentes entre si, com os valores aumentando do manejo 0,5 para 0,8 (Tabela 5). Para os solos Oásis, São Gabriel, Santa Maria, São Pedro, Venda Grande, Cerrito e Vacacaí, os menores valores do número de irrigações médio foram encontrados para os manejos 0,5 e 0,6, que não diferiram estatisticamente e foram seguidos das médias encontradas para os manejos 0,7 e 0,8 , respectivamente.

O aumento dos valores de lâmina de irrigação e do número de irrigações com o aumento dos valores de percentagem da CAD, utilizados no manejo da irrigação, era esperado, como explicado anteriormente, e segue a tendência da lâmina de irrigação.

Os valores de lâmina de irrigação encontrados foram inferiores aos relatados para o Paraná (Oliveira \& Villa Nova, 1996), mas bastante semelhantes aos valores de deficiência

Tabela 6. Valores médios do número de irrigações ( $\mathrm{N}$. Irrig.), totalizados em cada período de cultivo, solos e épocas de semeadura (ES), estudados na simulação do ciclo do feijoeiro, durante o período de 1968 a 2006, para os solos Alto das Canas, Cambaí, Charrua, Ciríaco, Guassupi, Júlio de Castilhos, Oásis e São Gabriel (a) e para os solos Santa Maria, São Pedro, Venda Grande, Cerrito e Vacacaí (b)

\begin{tabular}{cclll}
\hline ES & Solo & $\begin{array}{c}\text { Num. } \\
\text { Irrig. (a) }\end{array}$ & Solo & $\begin{array}{c}\text { Num. } \\
\text { Irrig. (b) }\end{array}$ \\
$15 / 08$ & & $2,6 \mathrm{D}$ & & $1,9 \mathrm{C}$ \\
$01 / 09$ & & $2,9 \mathrm{D}$ & & $2,1 \mathrm{BC}$ \\
$15 / 09$ & & $3,2 \mathrm{CD}$ & & $2,3 \mathrm{BC}$ \\
$01 / 10$ & Alto das & $3,8 \mathrm{BC}$ & & $2,4 \mathrm{BC}$ \\
$15 / 10$ & Canas, & $4,2 \mathrm{BC}$ & Santa Maria & $2,7 \mathrm{ABC}$ \\
$01 / 11$ & Cambaí & $4,5 \mathrm{AB}$ & & $3,0 \mathrm{AB}$ \\
$15 / 11$ & & $5,3 \mathrm{~A}$ & & $3,4 \mathrm{~A}$ \\
$15 / 01$ & & $3,8 \mathrm{BCD}$ & & $2,9 \mathrm{ABC}$ \\
$01 / 02$ & & $3,1 \mathrm{D}$ & & $2,2 \mathrm{BC}$ \\
$15 / 02$ & & $2,8 \mathrm{D}$ & & $2,1 \mathrm{BC}$ \\
\hline $15 / 08$ & & $3,5 \mathrm{EFG}$ & & $2,7 \mathrm{C}$ \\
$01 / 09$ & & $4,0 \mathrm{DEF}$ & & $2,9 \mathrm{C}$ \\
$15 / 09$ & Charrua, & $4,5 \mathrm{BCDE}$ & & $3,2 \mathrm{BC}$ \\
$01 / 10$ & Ciríac0, & $5,1 \mathrm{ABCD}$ & São Pedro, & $3,4 \mathrm{BC}$ \\
$15 / 10$ & Guassupi, & $5,4 \mathrm{ABC}$ & Venda & $3,8 \mathrm{BC}$ \\
$01 / 11$ & $5,9 \mathrm{~A}$ & Grande e & $4,2 \mathrm{AB}$ \\
$15 / 11$ & Júlio de & $6,5 \mathrm{~A}$ & Cerrito & $4,8 \mathrm{~A}$ \\
$15 / 01$ & Castilhos & $4,3 \mathrm{CDE}$ & & $3,7 \mathrm{BC}$ \\
$01 / 02$ & & $3,0 \mathrm{FG}$ & & $3,0 \mathrm{C}$ \\
$15 / 02$ & & $2,6 \mathrm{G}$ & & $2,7 \mathrm{C}$ \\
\hline $15 / 08$ & & $2,1 \mathrm{D}$ & & $1,9 \mathrm{E}$ \\
$01 / 09$ & & $2,3 \mathrm{CD}$ & & $2,1 \mathrm{DE}$ \\
$15 / 09$ & & $2,6 \mathrm{CD}$ & & $2,3 \mathrm{CDE}$ \\
$01 / 10$ & & $2,8 \mathrm{BCD}$ & & $2,8 \mathrm{BCDE}$ \\
$15 / 10$ & 0ásis, São & $3,2 \mathrm{BC}$ & Vacacaí & $3,2 \mathrm{BCD}$ \\
$01 / 11$ & Gabriel & $3,6 \mathrm{AB}$ & & $3,6 \mathrm{AB}$ \\
$15 / 11$ & & $4,0 \mathrm{~A}$ & & $4,3 \mathrm{~A}$ \\
$15 / 01$ & & $3,0 \mathrm{BCD}$ & & $3,5 \mathrm{ABC}$ \\
$01 / 02$ & & $2,5 \mathrm{CD}$ & & $2,6 \mathrm{BCDE}$ \\
$15 / 02$ & & $2,2 \mathrm{D}$ & & $2,5 \mathrm{CDE}$ \\
\hline
\end{tabular}

* Médias não seguidas de mesma letra na vertical, diferem pelo teste de Tukey em nível de 5\% de probabilidade de erro 
hídrica para a região do Planalto Médio do RS (Matzenauer et al., 2004). Este resultado é teoricamente correto, pois a tendência à similaridade entre as duas regiões pode estar associada a uma provável compensação relativa do efeito da menor temperatura com a maior insolação no Planalto Médio do RS em relação a Santa Maria.

A comparação dos valores de lâmina de irrigação entre ES não foi realizada, pois a interação solo x ES não foi significativa. $\mathrm{Na}$ comparação dos valores do número de irrigações para os solos Alto das Canas, Cambaí, Oásis e São Gabriel, observaramse as maiores médias para as ES de 01/11 e 15/11, valores intermediários para as ES de 15/09 até 15/10 e os menores valores para o início da safra e para todas as ES da safrinha (Tabela 6).

Para os solos Santa Maria, São Pedro, Venda Grande, Cerrito e Vacacaí, os maiores valores do número de irrigações foram observados para as ES de 15/10 a 15/11, em torno de quatro a seis aplicações de irrigação, e as demais foram semelhantes, com valores em torno de duas a quatro vezes por ciclo de cultivo. Para os solos com menor CAD (Charrua, Ciríaco, Guassupi, Júlio de Castilhos) foram previstas de três a cinco irrigações, no início da safra e na safrinha e para as ES de 01/10 a 15/11 foram previstas de cinco a sete irrigações.

\section{ConclusõEs}

1. A lâmina média de irrigação necessária para o feijoeiro por ciclo varia de 44,5 a 53,7 mm e o número de irrigações médio varia entre 2,6 a 4,6, conforme a capacidade de armazenamento de água do solo considerado.

2. Nos solos em que a capacidade de armazenamento de água disponível é menor, o número de anos com irrigação foi maior em relação aos demais solos e é pouco variável ao longo das épocas de semeadura.

3. A lâmina e o número de irrigações foram maiores nas épocas de semeadura do final da safra (15/10 a 15/11), menores na safrinha (15/01 a 15/02) e intermediários no início da safra.

\section{LITERATURA CITADA}

Bergamaschi, H.; Vieira, H. J.; Ometo, J. C.; Angelocci, L. R.; Libardi, P. L. Deficiência hídrica em feijão I. Análise de crescimento e fenologia. Pesquisa Agropecuária Brasileira, v.23, p.733-743, 1988.

Cardoso, C. D. V. Probabilidade de ocorrência de deficiência hídrica nos solos da região Central do Estado do Rio Grande do Sul. UFSM. Santa Maria: 2005. 162p. Tese Doutorado
Doorenbos, J.; Kassan, A. H. Efeito da água no rendimento das culturas. Campina Grande: UFPB, 1994. 306p. Estudos FAO. Irrigação e Drenagem, 33

EMBRAPA - Empresa Brasileira de Pesquisa Agropecuária. Feijão: O produtor pergunta, a EMBRAPA responde. Brasília. Embrapa Informação Tecnológica, 2003. 203p.

Frizzone, J. A.; Andrade Júnior, A. S.; Souza, J. L. M.; Zocoler, J. L. Planejamento de irrigação: Análise de decisão de investimentos. Brasília, DF: Embrapa Informação Tecnológica, 2005. 626p.

Heldwein, A. B.; Buriol, A. G.; Streck, N. A. O clima de Santa Maria. Ciência \& Ambiente, v.38, p.43-58. 2009.

Maluf, J. R. T.; Cunha, G. R.; Matzenauer, R.; Pasinato, A.; Pimentel, M. B. M.; Caiaffo, M. R. Zoneamento de riscos climáticos para a cultura de feijão no Rio Grande do Sul. Revista Brasileira de Agrometeorologia, v.9, p.468-476, 2001.

Matzenauer, R.; Maluf, J. R. J.; Bueno, A. C. Relações entre a evapotranspiração máxima do feijoeiro (Phaseolus vulgaris L.) com a evapotranspiração de referência e com a radiação solar global. Revista Brasileira de Agrometeorologia, v.7, p.173-178, 1999.

Matzenauer, R.; Maluf, J. R. T.; Barni, N. A.; Radin, B.; Anjos, C. S. Estimativa do consumo relativo de água para a cultura do feijoeiro na região do Planalto Médio do Rio Grande do Sul. Ciência Rural, v.34, p.1363-1369, 2004.

Medeiros, G. A.; Arruda, F. B.; Sakai, E.; Fujiwara, M.; Boni, N. R. Crescimento vegetativo e coeficiente de cultura do feijoeiro relacionados a graus-dia acumulados. Pesquisa Agropecuária Brasileira, v.35, p.1733-1742, 2000.

Nied, A. H.; Heldwein, A. B.; Estefanel, V.; Silva, J. C.; Alberto, C. M. Épocas de semeadura do milho com menor risco de ocorrência de deficiência hídrica no município de Santa Maria, RS, Brasil. Ciência Rural, v.35, p.995-1002, 2005.

Oliveira, D.; Villa Nova, N. A. Evapotranspiração máxima e lâminas de irrigação necessárias para o feijoeiro (Phaseolus vulgaris L.) no Paraná. Revista Brasileira de Agrometeorologia. v.4, p.29-36, 1996.

Streck, E. V.; Kämpf, N.; Dalmolin, R. S. D.; Klamt, E.; Nascimento, P. C.; Schneider, P.; Giasson, E.; Pinto, L. F. S. Solos do Rio Grande do Sul. 2.ed. Porto Alegre: EMATER/RS, 2008. 222p.

Silva, J. C.; Heldwein, A. B.; Martins, F. B.; Maass, G. F. Simulação para determinação das épocas de semeadura com menor risco de estresse hídrico para o feijão na região central do Rio Grande do Sul. Irriga, v. 11, n.2, p. 188-197, 2006.

Silva, J. C.; Heldwein, A. B.; Martins, F. B.; Streck, N. A.; Guse, F. I. Risco de estresse térmico para o feijoeiro em Santa Maria, RS. Ciência Rural, v.37, p.643-648, 2007. 